\title{
Systemic Cytokine Response predicts the Outcome of Patients from Mechanical Ventilation
}

\author{
${ }^{1}$ Akila Prashant, ${ }^{2}$ Prashant Vishwanath, ${ }^{3}$ Nalini Kotekar, ${ }^{4}$ Suma M Nataraj, ${ }^{5}$ Caroline Kuruvilla \\ ${ }^{6}$ CS Nagalakshmi, ${ }^{7}$ Parveen Doddamani
}

\begin{abstract}
Purpose: Despite the lifesaving potential, mechanical ventilation (MV) imposes a considerable amount of mechanical stress on the lung. Pulmonary and systemic cytokine release due to inflammatory process triggered by MV may give valuable information on patient outcome.
\end{abstract}

Materials and methods: Thirty patients aged $>18$ years with acute respiratory distress who required MV were enrolled for the study. Three milliliters of the venous blood was collected immediately after the initiation of MV and at 24 hours. Serum levels of interleukin (IL)-6, IL-8 and, tumor necrosis factor- $\alpha$ (TNF- $\alpha$ ) were estimated using quantitative immunometric sandwich enzyme immunoassay technique. Based on their outcome from MV, they were divided into two groups: Survivors (group I) and nonsurvivors (group II).

Results: Serum levels of IL-6 and IL-8 significantly increased in group II $(n=13)$ when compared with group I $(n=17)(p<0.0001$ and $p<0.001$ respectively) at 24 hours of MV. However, TNF- $\alpha$ did not show any significant difference between the two groups. The IL- $6>111.9 \mathrm{pg} / \mathrm{mL}$ at 24 hours of MV increases the probability of mortality by factor 2.40 . An increase of IL-6 by $1 \mathrm{pg} / \mathrm{mL}$ significantly increases the relative probability of mortality by a factor of $1.004(95 \% \mathrm{Cl}, 1.0003-1.0078, \mathrm{p}=0.0001)$.

Conclusion: Estimating the levels of IL-6 and IL-8 at 24 hours of connecting the patient to MV will help in predicting the outcome of the patient.

Keywords: Cytokines, Interleukin-6, Interleukin-8, Mechanical ventilation, Tumor necrosis factor- $\alpha$.

How to cite this article: Prashant A, Vishwanath P, Kotekar N, Nataraj SM, Kuruvilla C, Nagalakshmi CS, Doddamani P.

\footnotetext{
${ }^{1,3,4}$ Professor, ${ }^{2}$ Professor and Head, ${ }^{5}$ Postgraduate Student

${ }^{6}$ Assistant Professor, ${ }^{7}$ Officer-in-charge

1,2,4,7 Department of Biochemistry, Jagadguru Sri Shivarathreeswara Medical College \& Hospital, Jagadguru Sri Shivarathreeswara University, Mysuru, Karnataka, India

${ }^{3,5}$ Department of Anaesthesia, Jagadguru Sri Shivarathreeswara Medical College \& Hospital, Jagadguru Sri Shivarathreeswara University, Mysuru, Karnataka, India

${ }^{6}$ Department of Biochemistry, Akash Institute of Medical Sciences and Research Centre, Bengaluru, Karnataka, India

Corresponding Author: Akila Prashant, Professor, Department of Biochemistry, Jagadguru Sri Shivarathreeswara Medical College \& Hospital, Jagadguru Sri Shivarathreeswara University Mysuru, Karnataka, India, Phone: +919008097970, e-mail: akila. prashant@gmail.com
}

Systemic Cytokine Response predicts the Outcome of Patients from Mechanical Ventilation. Indian J Med Biochem $2017 ; 21(1): 5-10$.

\section{Source of support: Nil}

Conflict of interest: None

\section{INTRODUCTION}

Over the past 30 to 40 years, mechanical ventilation (MV) has become an indispensable therapeutic modality for the management of respiratory failure. However, soon after its inception, it became apparent that MV per se could lead to a number of deleterious complications, including initiation or exacerbation of underlying lung injury. ${ }^{1}$ Research over the past two decades has focused primarily on the mechanical factors (i.e., pressure and volume) that affect ventilator-induced lung injury (VILI). ${ }^{2-4}$ Despite considerable amount of experimental work and a number of innovations in ventilator therapy aimed at minimizing such injury, the morbidity and mortality of acute respiratory failure remain high, and VILI remains a significant problem in the care of critically ill patients. The concept of VILI came into light after animal experimental studies clearly demonstrated that MV with high airway pressure and tidal volume led to a rapidly developing permeability-type pulmonary edema with diffuse alveolar damage accompanied by severe lung inflammation when protracted. High lung volume rather than pressure was identified as responsible for these abnormalities, hence the term volutrauma. ${ }^{5}$

Earlier, generous tidal volumes $\left(\mathrm{V}_{\mathrm{T}}\right)(15-20 \mathrm{~mL} / \mathrm{kg})$ were delivered to patients to provide adequate $\mathrm{CO}_{2}$ elimination and counterbalance the formation of atelectasis. In the following years, practices progressively moved toward a reduction of tidal volume to values lower than $10 \mathrm{~mL} / \mathrm{kg}$ and interestingly it was associated with a more rapid attenuation of the inflammatory response. ${ }^{6,7}$ Definite proof of a causal relation between mortality and ventilator strategy was given by the results of a multicenter randomized controlled trial that showed a decreased mortality rate of $22 \%$ in patients ventilated with a $6 \mathrm{~mL} / \mathrm{kg}$ rather than a $12 \mathrm{~mL} / \mathrm{kg} \mathrm{V}_{\mathrm{T}}{ }^{8}$

The airway epithelium being the primary site at which lung tissue is exposed to various physiochemical stress 
factors serves as a target and mediator of inflammation via production of cytokines and chemokines from the lung soon after initiation of MV. ${ }^{9}$ Isolated, unperfused rat lungs when ventilated for 2 hours with strategies aimed at increasing lung MV stress released significant amounts of proinflammatory tumor necrosis factor- $\alpha$ (TNF- $\alpha$ ), interleukin (IL)-1 $\beta$, IL-6, and anti-inflammatory (IL-10) cytokines, as well as the chemokine macrophage inflammatory protein (MIP)-2 into airspaces. ${ }^{10}$ The TNF- $\alpha$ and IL-6 have also been detected in the perfusate of isolated mouse lungs ventilated with a large $\mathrm{V}_{\mathrm{T}}{ }^{11}$

The VILI may be difficult to diagnose in humans because its appearance may overlap the damage associated with the primary disease for which MV was instituted. In addition to increasing the amount of cytokines in the lung, it has been suspected that overinflation during MV may promote the release of cytokines into the blood. ${ }^{12}$ High circulating and tissue levels of proinflammatory cytokines, such as TNF- $\alpha$ and IL-6, appear to be contributing factors toward the development of a systemic inflammatory response that produces or aggravates lung damage and may lead to multiple organ failure. ${ }^{11}$ In this study, we correlated the circulating levels of cytokines like IL-6, IL-8, and TNF- $\alpha$ at 0 and 24 hours of MV with the outcome of patients from MV.

\section{MATERIALS AND METHODS}

Type of study: Prospective follow-up study.

\section{Inclusion Criteria}

Thirty patients (age $>18$ years) admitted to the intensive care unit (ICU) of a tertiary care hospital with acute respiratory distress and who required volume-controlled continuous MV for at least 24 hours were enrolled for the study. Approval from the institutional ethical committee was taken before commencement of the study. Written consent was taken from the patient's relatives before collection of blood.

\section{Exclusion Criteria}

Patients with sepsis, neuromuscular diseases, left ventricular dysfunction, chest or abdominal trauma, injury due to burns, and history of exacerbation of chronic respiratory failure during the last 3 months were excluded from the study.

\section{Sample Size}

All the occurrences in 6 months between July 2015 and December 2015 were included in the study. There were 176 admissions to the ICU during the study period. Out of these, 35 had acute respiratory distress and were intubated. Five patients were excluded from the study as two of them had pulmonary edema due to left ventricular dysfunction; two of them had exacerbation of chronic respiratory failure; and one was weaned from MV before 24 hours. Hence, 30 patients were included in the study.

Data collected from the patients' record included age, sex, underlying disease, and sequential organ failure assessment (SOFA) score within 24 hours after the patient was connected to $\mathrm{MV}$, documentation of the need for MV, and duration of MV. Strict input-output chart was maintained for all the patients to estimate their fluid balance. About $3 \mathrm{~mL}$ of the venous blood was collected immediately and at 24 hours after the patient was put on MV and centrifuged at 3,000 rpm for 10 minutes; serum was stored at $80 \mathrm{C}$ until further analysis. At the end of the study period, once 30 samples were collected, levels of IL- 6 , IL-8, and TNF- $\alpha$ were estimated in duplicate (with the technician blinded to the patient outcome from MV) using a solid-phase enzyme-linked immunosorbent assay method based on the quantitative immunometric sandwich enzyme immunoassay technique following the manufacturer's instructions.

On ICU admission, the following standard ventilation protocol was applied: Patients were continuously sedated (benzodiazepines and/or opioids), remained supine, and were ventilated with volume-controlled continuous MV. Respiratory rate and fraction of inspired oxygen $\left(\mathrm{FIO}_{2}\right)$ were adjusted to maintain arterial oxygen saturation $>90 \%$, partial pressure of carbon dioxide $\left(\mathrm{PaCO}_{2}\right)$ of 35 to $45 \mathrm{~mm}$ $\mathrm{Hg}$, and $\mathrm{pH}>7.25$. Tidal volumes of all the patients were between 5 and $7 \mathrm{~mL} / \mathrm{kg}$ of the predicted body weight. Positive end-expiratory pressure (PEEP) was kept at $10 \mathrm{~cm}$ $\mathrm{H}_{2} \mathrm{O}$. The inspiratory: expiratory (I:E) ratio was 1:2.

\section{Duration of Mechanical Ventilation}

Duration of MV was calculated from the time the patient was intubated and connected to ventilator till the time he was disconnected from the ventilator. A combination of subjective and objective parameters was used to wean the patient from MV. The objective parameters used were (a) $\mathrm{PaO}_{2} / \mathrm{FiO}_{2}>150-200$; (b) level of PEEP between 5 and $8 \mathrm{~cm} \mathrm{H}_{2} \mathrm{O}$; (c) $\mathrm{FiO}_{2}$ level < 50\%; (d) pH > 7.25; and (e) ability to initiate spontaneous breaths. The subjective parameters used were (a) hemodynamic stability; (b) absence of active myocardial ischemia; (c) absence of clinically significant vasopressor requiring hypotension; and (d) adequate muscular strength allowing the capability to initiate/sustain the respiratory effort. Patients were classified as survivors if they were successfully weaned and discharged without any episode of reintubation. Based on their outcome from MV, the patients were divided into two groups: Survivors (group I) and nonsurvivors (group II). 
Systemic Cytokine Response predicts the Outcome of Patients from Mechanical Ventilation

Table 1: Number of patients, mean age, SOFA score, and duration of MV of the patients in the two groups

\begin{tabular}{lll}
\hline Groups & $\begin{array}{l}\text { Group I } \\
\text { (survivors) }\end{array}$ & $\begin{array}{l}\text { Group II } \\
\text { (nonsurvivors) }\end{array}$ \\
\hline No. of patients (male/female) & $17(13 / 4)$ & $13(7 / 6)$ \\
Age in years & $46.9 \pm 19.8$ & $43.0 \pm 14.1$ \\
SOFA score at admission & $5.4 \pm 2.8$ & $6.0 \pm 3.4$ \\
SOFA score at 24 hours & $6.2 \pm 3.1$ & $11.1 \pm 3.6^{\mathrm{a}}$ \\
Duration of MV (days) & $4(2-6$ days) & $7(3-10$ days) \\
\hline $\mathrm{a}_{\mathrm{p}}<0.001$ & &
\end{tabular}

\section{Statistical Analysis}

Arithmetic mean and standard deviation were estimated to assess the level of various parameters in the study. Differences in the levels of IL- 6 , IL- 8 , and TNF- $\alpha$ between the defined groups were assessed using the Mann-Whitney nonparametric $U$ test. Sensitivity, specificity, positive predictive value (PPV), negative predictive value (NPV), and positive or negative likelihood ratios ( \pm LRs) for IL-6, IL-8, and TNF- $\alpha$ in predicting the outcome of patients from MV were calculated. Also, receiver operative characteristic (ROC) curves were constructed for each of the predictive variables and the areas under the ROC curves (AUC) were compared. The analyses were facilitated with the use of the MedCalc 11.5.1.0 software packages. Stepwise logistic regression analysis was used to determine as to which of the above variable was an independent risk factor for predicting the outcome of patients from MV. Differences were considered significant if the $p$-value was $<0.05$.

\section{RESULTS}

The distribution of patients in the study groups along with their mean age, duration of MV, and SOFA score are shown in Table 1. Out of the 30 patients (21 males and 9 females) enrolled for the study, 17 patients successfully improved after MV support was given to them and 13 patients expired. The mean age of the survivors and nonsurvivors did not show any statistical significant difference ( $p$-value 0.56 ). There was no significant difference in the SOFA score at the time of admission. However, the SOFA at 24 hours after connecting to ventilatory support was significantly increased in group II when compared with group I.

The mean and standard deviation of different parameters in the two groups are shown in Table 2. The serum
Table 2: Mean and SD of different parameters in the two groups based on their outcome from mechanical ventilator

\begin{tabular}{lll}
\hline Parameters & $\begin{array}{l}\text { Group I } \\
\text { mean } \pm S D\end{array}$ & $\begin{array}{l}\text { Group II } \\
\text { mean } \pm \text { SD }\end{array}$ \\
\hline IL-6 $(\mathrm{pg} / \mathrm{mL})$ immediately after MV & $152.3 \pm 98.3$ & $168.6 \pm 101.4$ \\
IL-6 $(\mathrm{pg} / \mathrm{mL}) 24$ hours after MV & $161.2 \pm 188.7$ & $592.7 \pm 495.2^{\mathrm{a}}$ \\
$\mathrm{IL}-8(\mathrm{pg} / \mathrm{mL})$ immediately after MV & $70.4 \pm 65.2$ & $84.2 \pm 71.0$ \\
$\mathrm{IL}-8(\mathrm{pg} / \mathrm{mL}) 24$ hours after MV & $76.5 \pm 78.0$ & $236.1 \pm 67.6^{\mathrm{b}}$ \\
TNF- $\alpha(\mathrm{pg} / \mathrm{mL})$ immediately after & $16.2 \pm 10.5$ & $18.9 \pm 15.2$ \\
MV & & \\
TNF- $\alpha(\mathrm{pg} / \mathrm{mL}) 24$ hours after MV & $14.3 \pm 8.5$ & $16.5 \pm 11.4$ \\
\hline${ }^{\mathrm{a}} \mathrm{p}<0.0001 ;{ }^{\mathrm{b}} \mathrm{p}<0.001 ;$ SD: Standard deviation &
\end{tabular}

levels of IL-6, IL-8, and TNF- $\alpha$ were not significantly different in the survivors and nonsurvivors immediately after they were connected to MV. However, the serum levels of IL- 6 and IL-8 increased significantly in the nonsurvivors when compared with the survivors $(p<0.0001$ and $p<0.001$ respectively) at 24 hours of MV. The levels of TNF- $\alpha$ did not show any significant difference in the two groups.

The sensitivity, specificity, PPV, NPV, positive or negative LR, and AUC to predict the outcome of the patient from MV at 24 hours are shown in Table 3 and Graphs 1A to C. The TNF- $\alpha$ had high specificity or PPV for predicting the outcome from MV at 24 hours, whereas IL-6 had high sensitivity or NPV for this purpose. The IL-6 $>111.9 \mathrm{pg} / \mathrm{mL}$ or IL-8 $>88.9 \mathrm{pg} / \mathrm{mL}$ at 24 hours of MV increase the probability of mortality by factor 2.40 or 2.62 respectively. By performing stepwise logistic regression analysis, it was shown that the most powerful predictor of outcome of patients from MV was serum IL-6 levels. An increase of IL-6 by $1 \mathrm{pg} / \mathrm{mL}$ significantly increases the relative probability of mortality by a factor of 1.004 (95\% CI, 1.0003-1.0078, $\mathrm{p}=0.0001$ ).

\section{DISCUSSION}

Injurious MV has a direct effect on pulmonary and systemic immune responses. Our results exemplify that patients who had high circulating levels of IL-6 and IL-8 had bad prognosis and could not survive the MV when compared with those who had low circulating levels of these cytokines. In vitro studies using human alveolar macrophage cultures and ex vivo preparations of rat and mice lungs, 1,11 "stretched" with injurious ventilator strategies have demonstrated an upregulation of cytokine

Table 3: Predictive ability of IL-6, IL-8, and TNF- $\alpha$ for outcome of the patients from MV at 24 hours

\begin{tabular}{llllllllll}
\hline Variable & Cutoff point & Sensitivity & Specificity & PPV & NPV & AUC & $+L R$ & $-L R$ & $p$-value \\
\hline IL-6 $(\mathrm{pg} / \mathrm{mL})$ & 111.9 & 84.6 & 64.7 & 64.7 & 84.6 & $0.819^{*}$ & 2.40 & 0.24 & 0.0001 \\
IL-8 $(\mathrm{pg} / \mathrm{mL})$ & 88.9 & 61.5 & 76.5 & 66.7 & 72.2 & 0.683 & 2.62 & 0.50 & 0.0782 \\
TNF- $\alpha(\mathrm{pg} / \mathrm{mL})$ & 24.3 & 30.8 & 100 & 100 & 65.4 & 0.577 & 0.00 & 0.69 & 0.5078 \\
\hline
\end{tabular}

${ }^{*} p<0.05$ vs TNF- $\alpha$ 

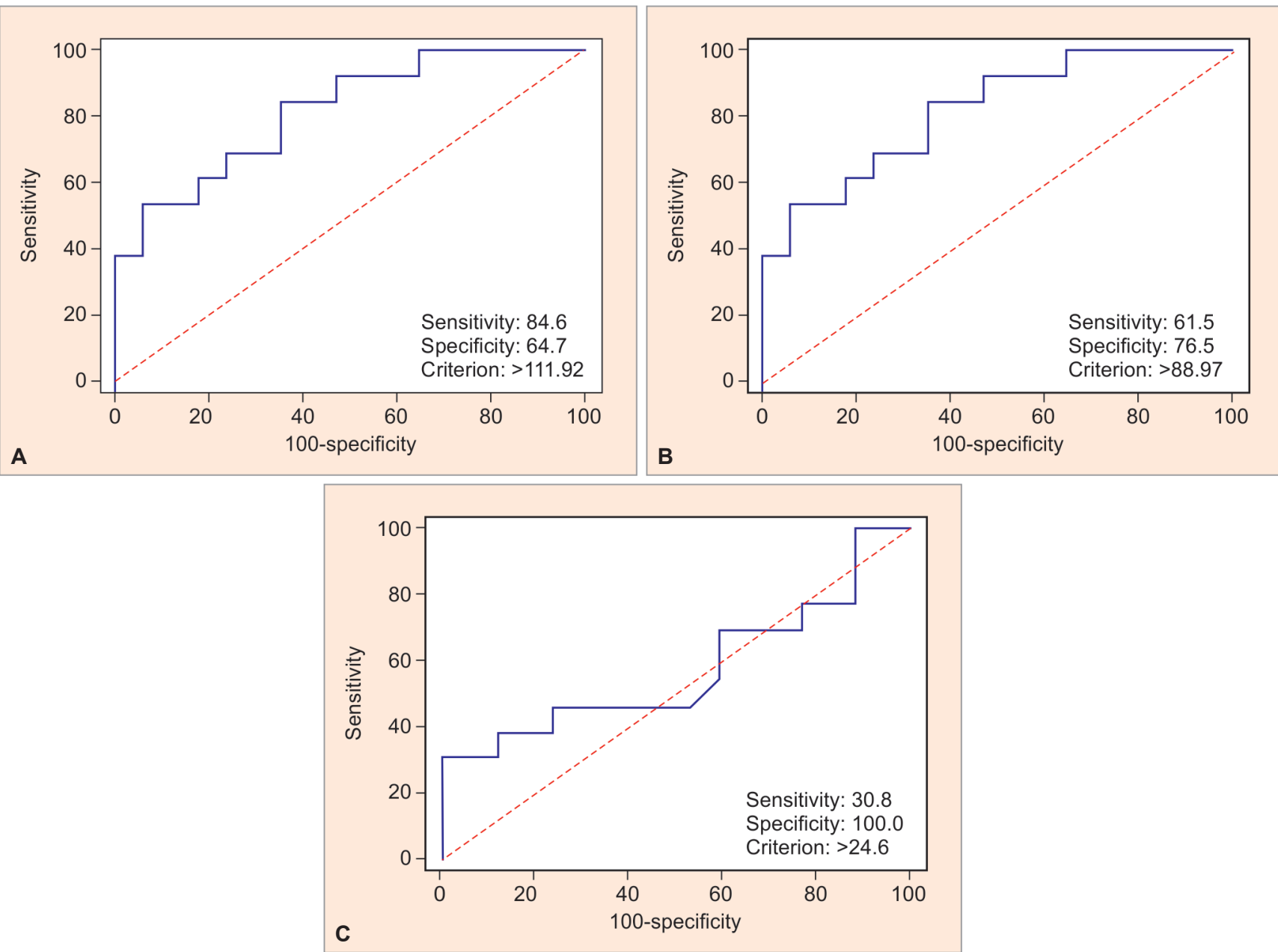

Graph 1A to C: The ROC curves for each of the predictive variables (A-IL-6, B-IL-8, C-TNF- $\alpha$ )

response, which may also lead to a systemic cytokine response in vivo. ${ }^{11,12}$ The present study has been undertaken to assess the change in the levels of cytokines after 24 hours of ventilation and its relation with the outcome of the patient.

The most frequently observed and most severe clinical manifestations of organ failure are seen in the lungs. Many conditions lead to the development of acute respiratory distress syndrome (ARDS) and end in multiorgan failure. Sepsis, aspiration of gastric contents, trauma, multiple transfusions, pneumonia, smoke inhalation as well as other pulmonary insults have been implicated in the genesis. Irrespective of the cause, the triggering event need not be initiated in the lung itself. In severe acute pancreatitis, the organ system most often involved in early (within 24 hours) single-organ failure is the pulmonary system $(91 \%)$. Extensive neutrophil infiltration of the lungs and also of other distant organs is a characteristic finding in patients dying of sepsis, and the degree of oxidative stress and of neutrophil activation and infiltration, especially in the lungs, appears to be the main determining factor of outcome. Acute lung injury is characterized by alveolar capillary endothelial cell injury, increased capillary permeability and subsequent hypoxia, and an accumulation of the neutrophil associated inflammatory products and other mediators. ${ }^{13}$

The MV may cause lung injury through the excitation of an inflammatory response and the release of mediators known as cytokines. Cytokines are low-molecular-weight soluble proteins produced by a wide variety of cells that transmit signals between the cells involved in the inflammatory response. The cytokines involved are IL-8 and CXC chemokines and probably IL- 6 , IL-1 $\beta$, and TNF- $\alpha$. In ARDS, high levels of cytokines, such as IL- 6 are present both in the lung and systemically. It is hypothesized that the lung itself can be an important cytokine-producing organ, such as when lung infection or inflammation is poorly contained. In these cases, pulmonary release of cytokines leads to elevations in their systemic levels. The VILI associated with the use of large tidal volumes has been shown to be associated with increased pulmonary cytokine production, which then leads to elevations in circulating concentrations. ${ }^{14,15}$

The MV triggers a process referred to as mechanotransduction, which refers to alterations in cytoskeletal structure without ultrastructural damage. In addition 
to this, direct trauma to the plasma membrane of alveolar cells and loss of cell integrity lead to the release of intracellular cytokines to the interstitium and decompartmentalization into both the alveolar space and the systemic circulation. In patients with ARDS, the highest cytokines are found downstream from the lung. This, in turn, reaffirms that biotrauma is not only confined to the lungs, but may also result in a systemic inflammatory response syndrome (SIRS) and distant organ apoptosis, both leading to multiorgan dysfunction and death. ${ }^{15-17}$

In a study by Wothuis et $\mathrm{al}^{18}{ }^{18}$ the patients scheduled to undergo an elective surgical procedure lasting $>5$ hours were randomly assigned to MV with either higher tidal volumes of $12 \mathrm{~mL} / \mathrm{kg}$ and no PEEP, i.e., zero positive end expiratory pressure (ZEEP), or lower tidal volume of $6 \mathrm{~mL} / \mathrm{kg}$ and $10 \mathrm{~cm} \mathrm{H} \mathrm{H}_{2} \mathrm{O}$ PEEP. After induction of anesthesia and 5 hours thereafter, bronchoalveolar lavage (BAL) fluid and/or blood was investigated for change in levels of inflammatory markers. This study demonstrated that even short-term MV is associated with significant inflammatory changes in the pulmonary compartment and that a lung-protective strategy attenuates these changes. The levels of inflammatory mediators in the BAL fluid are higher after 5 hours of MV with higher tidal volume and ZEEP as compared with the baseline levels. No increase in levels was seen after 5 hours of MV with lower tidal volume and PEEP. This implies activation of polymorphonuclear cells, which were recruited to the pulmonary compartment or already present there. This study proposed that lung injury is induced by a "multiplehit model," whereby predisposing conditions, such as injurious MV may result in pulmonary inflammation. A second hit, such as prolonged (injurious) MV may cause additional lung injury, finally resulting in full-blown ARDS with higher morbidity and mortality. There is also accumulating clinical evidence which supports this hypothesis. Higher $\mathrm{V}_{\mathrm{T}}$ ventilation was independently associated with development of ARDS in patients who did not have ARDS at the onset of MV in the ICU. ${ }^{18}$

Furthermore, postoperative patients who were ventilated with a lower $\mathrm{V}_{\mathrm{T}}$ strategy had a lower risk of pulmonary infection and duration of intubation and duration of stay tended to be shorter. ${ }^{19}$ In a study conducted by Ranieri et $\mathrm{al}^{20}$ a reduction in number of polymorphonuclear cells and proinflammatory mediators in the BAL fluid was demonstrated with a lung-protective strategy as compared with conventional MV in patients with ARDS. Fernández-Pérez et $\mathrm{al}^{21}$ showed that higher intraoperative $\mathrm{V}_{\mathrm{T}}$ is more associated with respiratory failure after pneumonectomy. Protective MV with lower $\mathrm{V}_{\mathrm{T}}$ and PEEP during esophagectomy resulted in a decrease in systemic proinflammatory response, improved lung function, and earlier extubation. ${ }^{21,22}$ Therefore, it can be said that even during a brief period of MV, patients will most likely benefit from lower $\mathrm{V}_{\mathrm{T}}$ and PEEP, which can, thereby, limit the proinflammatory changes in the lungs and the resulting SIRS. ${ }^{18}$

Our study aimed at demonstrating the increase in the levels of serum cytokines and, therefore, the prediction of the outcome from MV. This study showed an increase in the level of serum IL- 6 and IL- 8 in patients who did not survive MV, whereas the serum levels of TNF- $\alpha$ were not elevated in them. This could be due to the short half-life of TNF- $\alpha$ and/or complex formation with soluble receptors. The IL- 6 is a multifunctional cytokine induced by TNF- $\alpha,{ }^{23}$ which participates in acute inflammatory responses, and also promotes recruitment of neutrophils to injured tissue sites by induction of MIP-2, an analog of human IL-8. ${ }^{24}$ The duration of the MV in the two groups was comparable, and only one patient among the nonsurvivors was on ventilation for 10 days. Also, IL-6 >111.9 $\mathrm{pg} / \mathrm{mL}$ or IL- $8>88.9$ at 24 hours of MV increases the probability of mortality by factor 2.40 or 2.62 respectively. Hence, the estimation of the serum levels of IL-6 and IL-8 after the patient is put on MV might help the intensivist to know the lung status. Elevated levels of these cytokines may indicate overinflation and injurious MV and poor prognosis of the patient. Further studies can be taken up with large sample size and carrying out serial measurements of cytokines during the course of MV.

\section{REFERENCES}

1. Slutsky AS, Ranieri VM. Ventilator-induced lung injury. N Engl J Med 2013 Nov;369(22):2126-2136.

2. Lionetti V, Recchia FA, Ranieri VM. Overview of ventilatorinduced lung injury mechanisms. Curr Opin Crit Care 2005 Feb;11(1):82-86.

3. Uhlig S. Ventilation-induced lung injury and mechanotransduction: stretching it too far? Am J Physiol Lung Cell Mol Physiol 2002 May;282(5):L892-L896.

4. de Prost N, Ricard JD, Saumon G, Dreyfuss D. Ventilatorinduced lung injury: historical perspectives and clinical implications. Ann Intensive Care 2011 Jul;1(1):28.

5. Dreyfuss D, Rouby JJ. Mechanical ventilation-induced lung release of cytokines. Anesthesiology 2004 Jul;101:1-3.

6. Esteban A, Anzueto A, Frutos F, Alía I, Brochard L, Stewart TE, Benito S, Epstein SK, Apezteguía C, Nightingale P, et al. Characteristics and outcomes in adult patients receiving mechanical ventilation: a 28 day international study. JAMA 2002 Jan;287(3):345-355.

7. Parsons PE, Eisner MD, Thompson BT, Matthay MA, Ancukiewicz M, Bernard GR, Wheeler AP, NHLBI Acute Respiratory Distress Syndrome Clinical Trials Network. Lower tidal volume ventilation and plasma cytokine markers of inflammation in patients with acute lung injury. Crit Care Med 2005 Jan;33(1):1-6, discussion 23-232.

8. The Acute Respiratory Distress Syndrome Network, Brower RG, Matthay MA, Morris A, Schoenfeld D, Thompson BT, 
Wheeler A. Ventilation with lower tidal volumes as compared with traditional tidal volumes for acute lung injury and the acute respiratory distress syndrome. N Engl J Med 2000 May;342(18):1301-1308.

9. Wrigge $H$, Zinserling J, Stüber F, von Spiegel T, Hering R, Wetegrove S, Hoeft A, Putensen C. Effects of mechanical ventilation on release of cytokines into systemic circulation in patients with normal pulmonary function. Anesthesiology 2000 Dec;93(6):1413-1417.

10. Ricard JD, Dreyfuss D, Saumon G. Production of inflammatory cytokines in ventilator- induced lung injury: a reappraisal. Am J Respir Crit Care Med 2001 Apr;163(5):1176-1180.

11. von Bethmann AN, Brasch F, Nüsing R, Vogt K, Volk HD, Müller KM, Wendel A, Uhlig S. Hyperventilation induces release of cytokines from perfused mouse lung. Am J Respir Crit Care Med 1998 Jan;157(1):263-272.

12. Plötz FB, Slutsky AS, van Vught AJ, Heijnen CJ. Ventilatorinduced lung injury and multiple system organ failure: a critical review of facts and hypotheses. Intensive Care Med 2004 Oct;30(10):1865-1872.

13. Bierhaus A, Humpert PM, Nawroth PP. Linking stress to inflammation. Anesthesiol Clin 2006 Jun;24(2):325-340.

14. Fein AM, Abraham EM. Can we make sense out of cytokines? Chest 2000 Apr;117(4):932-934.

15. Halbertsma FJ, Vaneker M, Scheffer GJ, van der Hoeven JG. Cytokines and biotrauma in ventilator-induced lung injury: a critical review of literature. Neth J Med 2005 Nov;63(10): 382-392.

16. Pugin J. Molecular mechanisms of lung cell activation induced by cyclic stretch. Crit Care Med 2003 Apr;31(Suppl 4): S200-S206

17. Belperio JA, Keane MP, Lynch JP 3rd, Strieter RM. The role of cytokines during the pathogenesis of ventilator-associated and ventilator-induced lung injury. Semin Respir Crit Care Med 2006 Aug;27(4):350-364.

18. Wolthuis EK, Choi G, Dessing MC, Bresser P, Lutter R, Dzoljic M, van der Poll T, Vroom MB, Hollmann M, Schultz MJ. Mechanical ventilation with lower tidal volumes and positive end-expiratory pressure prevents pulmonary inflammation in patients without preexisting lung injury. Anesthesiology 2008 Jan;108(1):46-54.

19. Lee PC, Helsmoortel CM, Cohn SM, Fink MP. Are low tidal volumes safe? Chest $1990 \mathrm{Feb}$;97(2):430-434.

20. Ranieri VM, Suter PM, Tortorella C, , De Tullio R, Dayer JM, Brienza A, Bruno F, Slutsky AS. Effect of mechanical ventilation on inflammatory mediators in patients with acute respiratory distress syndrome: a randomized controlled trial. JAMA 1999 Jul;282(1):54-61.

21. Fernández-Pérez ER, Keegan MT, Brown DR, Hubmayr RD, Gajic O. Intraoperative tidal volume as a risk factor for respiratory failure after pneumonectomy. Anesthesiology 2006 Jul;105(1):14-18.

22. Michelet P, D'Journo XB, Roch A, Doddoli C, Marin V, Papazian L, Decamps I, Bregeon F, Thomas P, Auffray JP. Protective ventilation influences systemic inflammation after esophagectomy: a randomized controlled study. Anesthesiology 2006 Nov;105(5):911-919.

23. Martin C, Boisson C, Haccoun M, Thomachot L, Mege JL. Patterns of cytokine evolution (tumor necrosis factor-alpha and interleukin-6) after septic shock, hemorrhagic shock, and severe trauma. Crit Care Med 1997 Nov;25(11):1813-1819.

24. Romano M, Sironi M, Toniatti C, Polentarutti N, Fruscella P, Ghezzi P, Faggioni R, Luini W, van Hinsbergh V, Sozzani S, et al. Role of IL-6 and its soluble receptor in induction of chemokines and leukocyte recruitment. Immunity 1997 Mar;6(3):315-325. 